\title{
La tematización de lo sagrado en el pensamiento contemporáneo.*
}

The thematization of the sacred in contemporary thought.

Por: Gonzalo, César Ignacio*

UNNE

Resistencia, Argentina.

Email: cesignagon@gmail.com

Fecha de recepción: 29/08/2020

Fecha de aprobación: 23/10/2020

DOI: http://dx.doi.org/10.30972/nvt.1624490

\section{Resumen}

El siguiente escrito se propone trabajar sobre la noción de lo sagrado de acuerdo fue considerado en el pensamiento contemporáneo, período en el que se constituye en objeto de estudio específico, lográndose distinguir bajo contornos cada vez más precisos respecto al campo de saberes y prácticas referido a lo religioso. Más concretamente, nos referiremos a tres perspectivas desde las cuáles esta noción cobra especial relevancia para el campo de la filosofía, las ciencias sociales y humanas en general. Ellas son: a) la psicología de lo sagrado de Rudolf Otto; b) la fenomenología de lo sagrado de Mircea Eliade y; c) los desarrollos provenientes desde la antropología

\footnotetext{
* Este trabajo forma parte de una investigación personal iniciada en calidad de estudiante de grado y materializada por vez primera en el año 2018 en una publicación en la revista estudiantil Acheronta, Vol. № 3 (DOI: http://dx.doi.org/10.30972/ach.033083). Línea de investigación que seguirá presente en la realización y aprobación de la tesina de grado: "Hacia una reinterpretación de la noción de lo sagrado. La filosofía moral de Empédocles como punto de partida". 2020. Actualmente, dicha temática forma parte del plan de trabajo aprobado por Secretaría General de Ciencia y Técnica en calidad de beca de investigación.

* Licenciado en Filosofía por la Universidad Nacional del Nordeste. 2020. Becario por Secretaría General de Ciencia y Técnica, Res. № 1014/19 (categoría: Iniciación). Integrante del proyecto de investigación "Procesos de subjetivación e institucionalización en problemáticas filosóficas contemporáneas", №16H002. Secretaría Gral. C y T - UNNE. Período: 2017/2020. Estudiante del profesorado de filosofía (U.N.N.E).
} 
de lo sagrado en Rene Girard y Walter Burkert. A partir de lo señalado, se considera como objetivo central de este trabajo, el de evidenciar la problematicidad que caracteriza de modo esencial a la noción de lo sacro en lo que a todo intento de conceptualización clara y precisa refiere. En tal sentido, lo sagrado emerge como lo absolutamente otro, "lo inaprensible", en oposición al mundo profano, donde sí tendría objeto la capacidad racional del ser humano.

De forma previa a los desarrollos considerados como cuerpo central de este trabajo, nos interesa señalar un antecedente directo en lo que a la conceptualización de lo sagrado refiere. En razón de ello, nos detendremos en el pensamiento del teólogo y filósofo alemán Friedrich Schleiermacher, quién comenzará a dar forma desde la teoría, un marcado contraste entre dos fenómenos antaño asimilados: la religión y lo sagrado.

Palabras clave: Sagrado; profano; violencia; contemporaneidad; religión.

\begin{abstract}
The following writing proposes to work on the notion of the sacred as it was considered in contemporary thought, a period in which it constitutes a specific object of study, being able to distinguish under increasingly precise contours regarding the field of knowledge and practices referred to the religious. Specifically, we will refer to three perspectives from which this notion takes on special relevance for the field of philosophy and the social and human sciences in general. They are: a) the psychology of the sacred in Rudolf Otto; b) the phenomenology of the sacred by Mircea Eliade and; c) developments coming from the anthropology of the sacred. Based on the above, it is considered as the central objective of this work, to show the problematic nature that essentially characterizes the notion of the sacred as regards any attempt at clear and precise conceptualization. In this sense, the sacred emerges as the absolutely other, "the elusive", in opposition to the profane world, where the rational capacity of the human being has a place.
\end{abstract}


Prior to the developments considered as the central body of this work, we are interested in pointing out a direct antecedent regarding the conceptualization of the sacred. For this reason, we will stop at the thought of the German theologian and philosopher Friedrich Schleiermacher, who will begin to shape from theory, a marked contrast between two phenomena once assimilated: religion and the sacred.

Keywords: sacred; profane; violence; contemporaneity; religion.

\section{Cómo citar este artículo:}

APA: Gonzalo, C. I. (2020). La tematización de lo sagrado en el pensamiento contemporáneo. Nuevo Itinerario, 16 (2), 127-157. Recuperado de: (agregar dirección web)

\section{Introducción}

Si bien puede ser afirmado que será a partir de los últimos años del s. XIX y los inicios del siguiente donde la noción de lo sacro sea objeto de un profundo, pero sobretodo sistemático interés por parte de la filosofía y de las ciencias humanas, es posible observar desarrollos preliminares en el periodo moderno del pensamiento europeo, los cuales encontraremos referidos principalmente a la consideración del fenómeno religioso. Provenientes en su mayoría de la teología, pero también del campo de la filosofía y la poesía, estos estudios y abordajes sobre lo sagrado tendrán inicio aproximadamente en el s. XVIII, ${ }^{1}$ contenidos en el espíritu general de lo que ha sido denominado "el siglo de las luces". Al amparo de dicho movimiento, y a modo muy general, puede decirse que la teología cristiana se verá afectada por el desfondamiento de un importante contingente de premisas y saberes, ${ }^{2}$ provenientes en su mayoría del período medieval, las cuales la situaban en la cúspide de los saberes acerca de lo real. En el caso particular de la filosofía, esto podrá ser verificado en el

\footnotetext{
${ }^{1}$ Excepciones previas a este período pueden ser identificadas en algunas corrientes cristianas que combaten y denuncian las mediaciones sagradas (lucha contra la hagiografía), u otras corrientes herméticas o teosóficas, provenientes del neoplatonismo, ocupadas en reflexionar acerca de la simbología religiosa.

${ }^{2}$ En este período, es posible observar una primacía de reflexiones y desarrollos abocados a la existencia y naturaleza de Dios, como así también sobre las religiones y su rol institucional (constitución de la Iglesia y de los dogmas).
} 
surgimiento de reflexiones y desarrollos ocupados en la posibilidad de una religión natural. Bajo dicho contexto, los hechos religiosos se verán afectados por aproximaciones de corte racionalista y sistemática, con el fin de discernir en ellos los aspectos ficticios tenidos por oscurantistas, respecto a los rasgos tolerables, compatibles con el modelo ilustrado por la razón y el progreso.

Un claro exponente de esta época fue el teólogo y filósofo alemán Friedrich Schleiermacher (1768 - 1834), quién en los Discursos, ${ }^{3}$ un temprano trabajo de su prolífico pensamiento, llevará adelante algunas indagaciones sobre lo religioso en donde prima el interés sobre la experiencia del individuo sujeta a la vivencia de lo sagrado. Experiencia que en la opinión del teólogo alemán, nada tiene que ver con los modos en que la religión fuera concebida dentro del hegelianismo (forma de conocimiento) o en el kantismo (reducción de la religión a la moral). La religión, nos dirá Schleiermacher, "no es un pensamiento ni una acción, sino una intuición y un sentimiento" (1990, p. 23). En este sentido, la conciencia religiosa se aproxima más a la conciencia estética que al conocimiento teórico, ${ }^{4}$ con lo cual, las vías de acceso que el ser humano poseería respecto a la divinidad se sitúan lejos de una pretensión objetiva de conocimiento (fundamento tradicionalista y dogmático). En razón de esto es que Schleiermacher enuncia que lo esencial de la religión se manifiesta en la centralidad del sentimiento, el cual se despliega en una dependencia del sujeto ante lo absoluto.

Este sentimiento de dependencia ante lo absoluto o lo infinito pensado por Schleiermacher como meollo de la experiencia sagrada, cobra relevancia dentro de esta esquemática introducción en cuanto comienza a adquirir protagonismo una tendencia procesual de progresiva subjetivación de la experiencia religiosa, la cual, desprendida de su referente objetivo (Dios), es posible de ser comprendida solamente en la intimidad del sujeto. Con ello, se traza la posibilidad de un punto de partida en lo concerniente a lo religioso como objeto de estudio, en el cual es la experiencia

\footnotetext{
${ }^{3}$ Schleiermacher, Friedrich. Sobre la religión. Discursos a sus menospreciadores cultivados. Trad. de Arsenio Ginzo Fernández. Madrid, Tecnos, 1990.

4 Posicionamiento que puede ser comprendido en el pensamiento del teólogo berlinés como una tensión entre su impronta ilustrada y las influencias del romanticismo. En todo caso, fue una de sus mayores preocupaciones la de distinguir entre ambas "conciencias", evitando con ello una reducción de lo religioso en lo estético.
} 
humana la que se manifiesta decisiva a la hora de comprender su relación con lo divino. Opera en tal sentido, un descentramiento respecto al referente objetivo religioso dados los peligros dogmáticos que allí acechan al pretenderse delimitar una experiencia inabarcable desde lo conceptual. Esto, como lo veremos de forma más detallada en el apartado siguiente, se manifestará radicalmente agudizado desde las reflexiones de Rudolf Otto acerca de los momentos de la experiencia sagrada.

Sin pretender con esto abarcar una mínima porción de lo que en el pensamiento moderno tuvo lugar como reflexiones preliminares sobre lo sacro -lo cual aquí sería imposible en razón de su extensión-, queríamos mostrar una de las líneas principales bajo las cuales será trabajada a partir del s. XX. De este modo, y más allá de lo propio de la obra de Schleiermacher -la cual recorre temáticas sumamente diversas--, nos resultó de importancia poner en evidencia una nueva perspectiva bajo la cual lo religioso comienza a tornar en objeto de interés en el periodo moderno. Al manifestarse lo sagrado como experiencia particular de la Totalidad en la intuición y el sentimiento, la posibilidad de una aprehensión de la divinidad en definiciones claras y precisas, queda obstruida -posibilidad que Schleiermacher entenderá como tarea propia de la metafísica y ya no de la religión--. Procederá en este sentido, un incipiente movimiento de distinción entre la religión y lo sagrado, representado este último por los intentos de conformar un campo autónomo de reflexiones acerca de los modos en que el ser humano conforma su relación con lo religioso, siendo este último un efecto de aquella experiencia originaria de lo sacro, y que como veremos inmediatamente, cobrará nuevas aristas desde la introducción de elementos poco familiarizados respecto a la concepción clásica del sujeto religioso.

\section{La tematización de lo sacro en el pensamiento contemporáneo}

Nos dedicaremos a continuación y en lo que resta del artículo, a exponer algunos lineamientos y perspectivas bajo los cuales lo sagrado cobró relevancia en el pensamiento contemporáneo. ${ }^{5}$ Así entonces, si en el interior del pensamiento de

\footnotetext{
${ }^{5}$ Bajo intenciones similares es posible adscribir el siguiente artículo: Lorio, N. El devenir de la parte ambigua: momentos y motivos de lo sagrado (2015). Revista de filosofía: el laberinto de arena. Vol. 2, no 4 Verano/Otoño.
} 
Schleiermacher pudo ser ya esbozado un principio de desprendimiento entre lo sagrado y lo religioso, cobrando el primero un interés primordial en derredor al sujeto religioso (subjetivación de lo sagrado), las especulaciones oficiadas durante el periodo contemporáneo asegurarán un campo específico de nociones e instituciones bajo las cuales será posible deslindarlos de forma mucho más precisa. Las causas de esta distinción podemos atribuirlas a numerosas circunstancias, una de ellas sin duda, a la de cierto declive de lo religioso en Occidente. ${ }^{6}$ Ello se manifestará en el ateísmo filosófico de fines de s. XIX, notorio en el pensamiento de figuras de la talla de Friedrich Nietzsche y Ludwig Feuerbach, por tomar dos ejemplos significativos.

No obstante, dicha circunstancia debe ser considerada bajo ciertos atenuantes. La noción de lo sagrado, como podrá ser observado en primer lugar desde el pensamiento de Rudolf Otto, bajo ninguna circunstancia es trabajada con la intención de ser opuesta a lo religioso, más bien todo lo contrario. Frente a las concepciones reduccionistas que intentaban explicar la religión desde una perspectiva naturalista y racional, tendencia presente en pensadores como Ludwig Feuerbach y Karl Marx, las cuales contribuyeron a una corriente en la que se niega la existencia de Dios (ateísmo lógico), la tematización de lo sacro en Otto se enmarcará frente al desafío abierto por otra corriente, también referida al ateísmo, pero de una naturaleza diferente. Nos encontramos allí con un ateísmo de corte más bien emocional, que toma conciencia de lo que implica la ausencia de referentes trascendentales --caso del nihilismo nietzscheano y el absurdo planteado por Camus--. Es en respuesta a esta postura que debe ser comprendida la apertura temática de lo sacro propuesta por Otto, intentando con ella, llenar de sentido una experiencia que ya no tendrá como meta especulativa la de referenciar objetivamente una divinidad cualquiera, sino que del mismo modo que en Schleiermacher, se buscará dotarla de significado en lo que a la experiencia íntima y auténtica del sujeto imbuido por lo religioso refiere. Experiencia que por otro lado, si bien seguirá sometida a los designios del sentimiento, se liberará de aquellas

\footnotetext{
${ }^{6}$ En este mismo sentido, el filósofo francés Wunenburger, Jean - Jacques (1946), especializado en estudios sobre lo imaginario, nos dirá que "este interés por lo sagrado ha aumentado a medida que nuestras sociedades occidentales contemporáneas conocieron una declinación de lo religioso, un debilitamiento de lo sagrado que se había desprendido de aquél” (2006, pág. 9).
} 
construcciones abstractas que en Schleiermacher se consolidan en la dependencia a lo Absoluto o lo infinito.

De esta forma, será como efecto de un movimiento de radical subjetivación de la experiencia sagrada donde podrán ser evidenciados con llamativa presencia, elementos que podríamos comprender como inquietantes y desasosegantes en lo que a la experiencia religiosa refiere. El sentimiento de heiliger schauer (horror sagrado) frente a lo divino (Otto, 2009, pp. 17 - 19), es un manifiesto ejemplo en este sentido. A este, entre otros elementos conceptuales presentes en la concepción de lo sagrado en Otto, nos dedicaremos a indagar en el siguiente apartado.

\section{a) Rudolf Otto y el carácter irracional de la experiencia sagrada}

Rudolf Otto (1869-1937) fue un teólogo y erudito en el estudio comparativo de las religiones. Su obra en general influyó grandemente en los estudios acerca de la religión, especialmente a partir de la segunda mitad del s. XX. La más conocida de sus producciones, Lo Sagrado (Das Heilige), es considerada bibliografía de consulta obligatoria en lo que concierne a la temática. A ella nos remitiremos en lo inmediato a fin de considerar lo más exhaustivamente posible la idea bajo la cual este pensador hubo de concebir la noción de lo sagrado.

Ya en sus primeras páginas, el teólogo alemán nos ofrecerá una serie de nociones bajo las cuales debe concebirse toda idea teísta de Dios -dentro de la cual se incluye la cosmovisión cristiana- $(2008$, p. 13). Allí se nos dirá que la idea de divinidad es captable solo mediante predicados racionales y personales, los cuales se comprenden como atributos que la humanidad ha descubierto en sí misma a través de su desarrollo histórico (espíritu, voluntad, razón, etc.), las cuales le serán transferidas a aquella de forma apoteósica. Este atributo de racionalidad, nos dirá Otto, es la causa principal por la cual el cristianismo habrá de ser considerada como expresión religiosa superior a las demás (Otto, 2008, p. 13).

Una vez asegurado el puesto superior del cristianismo dentro de la escala jerárquica religiosa a causa de su ínsita racionalidad, Otto se ocupará de trabajar sobre un asunto que nos resulta aquí de vital importancia, pues aquellos predicados que 
cualifican de forma superior a toda religión -y en especial al cristianismo-- no señalarían en lo más mínimo la esencia de la divinidad. Con estas palabras nos lo indicará Otto: "Pero aunque los predicados racionales estén habitualmente en el primer plano, agotan tan poco la idea de la divinidad que ellos justamente valen y son sólo por algo irracional ${ }^{7}$ y en algo irracional" (2008, p. 14). El reconocimiento de este factor en el componente religioso, soslayado de suyo en gran parte de la tradición filosófica resulta de interés en cuanto permitirá la apertura de todo un campo de análisis. Apertura cargada de significado en tanto podrán ser detectados nuevos elementos bajo los cuales será posible replantear numerosos aspectos del fenómeno religioso. Es inmerso en tal espíritu desde donde contrastaremos el fenómeno religioso frente a la noción de lo sagrado, donde si bien el elemento cristológico aún se encuentra presente, ya no lo será de modo primordial.

Uno de los elementos a tener en cuenta dentro de dicha apertura es el referido a la concepción de tiempo dentro del paradigma sagrado. El carácter lineal y teleológico bajo el cual el cristianismo lo concibe, encuentra una importante diferencia en el orden de lo sagrado, donde su transcurrir responde más bien a ciclos y repeticiones. No hay continuidad, sino rupturas y re-comienzos. Esto quedará mayormente aclarado a partir de lo que Eliade desarrolle respecto a la forma en que lo sagrado vivencia al tiempo. Baste aquí considerar que el atributo racional que Otto dispone para el cristianismo, confluye con esta idea de tiempo lineal, homogénea y única, contraponiéndose a aquel predicado esencial de lo divino consumado en lo irracional, lo cual en algún punto dificulta una posible comprensión de la misma al tornarse en palabras del teólogo alemán, inasible al concepto (Otto, 2008, p. 15). En este aspecto, de acuerdo vayamos indagando en los sistemas teóricos que se ocupen de tematizar lo sagrado, la presencia cristiana irá progresiva y sustancialmente perdiendo relevancia hasta el punto de ser considerado un modo más de expresión religiosa entre otros.

\footnotetext{
${ }^{7}$ Por irracional, Otto comprende todo "suceso extraño que escapa por su profundidad a la explicación del entendimiento" (2008, pág. 79), ante lo cual la tarea encomendada sería "asentar sus momentos por caracterizaciones ideogramáticas lo más próximas posibles; afianzar por signos duraderos lo que fluctúa en la apariencia vacilante del mero sentimiento" (2008, pp. 80-81).
} 
La importancia del elemento irracional que Otto atribuirá a la divinidad será tal, que la catalogará como predicado esencial sintético en tanto se agregaría como algo fundamental al sujeto en el juicio (2008, pág. 14). ${ }^{8}$ El mayor problema que en este aspecto se le presentará al teólogo alemán es la manera de hacer comprensible aquel soporte sintético. Tal dificultad irá de la mano de la "tradicional" tendencia racionalista bajo la cual hubo de ser abordada la idea de Dios, lo cual ocultaría un rasgo esencial en la misma: el de la emoción e intimidad religiosa (Otto, 2008, pág. 15). Bajo tal aclaración es donde comenzará a ser esbozada la categorización específica de lo sagrado. Para ello, Otto recurrirá a un término con el que tratará de evocar lo más propio del ámbito divino, alejándose de las concepciones previas que lo ubicaban como "predicado absoluto moral o el bien perfecto" (2008, pág. 17) ${ }^{9}$ y de todo uso no riguroso del término. Esta noción, a la cual habrá que prestar atención dados sus orígenes muy escasamente relacionados con una idea de bien o una ética específica, es la de lo numinoso. ${ }^{10}$ En relación a dicha categoría se nos dirá que "nuestra $\mathrm{X}$ no es esto, pero está emparentada con esto y opuesta a aquello. Nuestra $\mathrm{X}$ no se puede enseñar, sino solo suscitar, despertar, como todo lo que procede del espíritu" (Otto, 2008, pág.

\footnotetext{
${ }^{8}$ La influencia del pensamiento kantiano es uno de los elementos más presentes en la obra de Otto. Fundamentalmente, dicho ascendente se encuentra sostenido teóricamente por lo que en Kant se constituyó como la preponderancia del sujeto en el acto cognoscitivo, siendo el predicado que se le atribuye a un determinado objeto, una expresión de la intencionalidad del sujeto, y no atributo del objeto mismo. Allí es donde Otto encontrará la llave para "decir algo" acerca de lo sagrado, pues si bien no resulta claramente comprensible, es innegable que responde a una intención de sentido (y no de significado). De este modo, y siguiendo al filósofo de Königsberg, Otto entenderá que lo sagrado es inaccesible para la comprensión, funcionando más bien como una categoría fundamentalmente valorativa, acercándose de este modo a lo que Kant entiende por predicado absoluto moral cuando este se refiere a "lo santo".

${ }^{9}$ Precisamente bajo este horizonte Otto ubicará la concepción de lo religioso comprendida por Immanuel Kant. Ello en razón de que este habrá de concebirla como voluntad santa o voluntad moral perfecta a raíz de la obediencia sin matices por el solo impulso del deber y la ley moral que genera (Otto, 2008. pág. 17). ${ }^{10} \mathrm{R}$. Otto explica que ha formado esta palabra combinando dos términos: omen (ominoso) y lumen (luminoso). Numen (de donde Otto deriva numinoso) alude en su origen al movimiento de cabeza por el cual se manifiesta la voluntad de prohibir o de permitir, y termina aplicándose a la voluntad divina que de ese modo expresa su poder. Mientras signum designa la manifestación sensible por la cual esta voluntad se da a conocer (hechos prodigiosos, fenómenos naturales), numen alude al ejercicio del poder supremo de un dios (Otto, 2008, pág. 16).

Por su parte, y en consideración del ascendente kantiano mencionado en notas precedentes, cabe ser realizada alguna aclaración en relación a los términos entre lo numinoso en Otto y el noúmeno en Kant. Las diferencias son notables al centrarnos de forma detallada en tales nociones. En primer lugar, pertenecen a etimologías diferentes. En el caso de Otto (del latín) indica la experiencia terrorífica (lo ominoso del numen) solo pasible de ser intuida. Por el lado de Kant (del griego), el noúmeno es objeto del conocimiento racional puro (objeto de intuición no sensible), en oposición al fenómeno, objeto del conocimiento sensible.
} 
19). Esto explica el hecho de que se la considere como dato fundamental y originario ( $a$ priori), indefinible, pasible solamente de ser elucidado. También nos ofrece un indicio de inigualable valor a la hora de comprender el modo bajo el cual Otto trabajará en adelante con la noción de lo sagrado. En principio se puede afirmar sin riesgo de caer en error, que su proyecto se encuentra muy lejos de una construcción conceptual, interrogante que en numerosas ocasiones hizo presencia a la hora de pensar este trabajo respecto al modo en que aquella noción fue abordada tras su liberación del supuesto cristiano. Más bien pareciera que allí opera una intención representativa en lo referente al orden originario de la práctica sagrada. Representación de una práctica que rememoraría el ámbito ritual y que buscaría ser experimentado en el plano psicológico del individuo.

Por su parte, lo numinoso será pasible de una mayor elucidación a partir de lo que el teólogo alemán desarrolle desde lo comprendido como momentos experienciales del mismo. El primero de estos momentos aludirá a un sentimiento pertinente bajo el cual es experimentada aquella emoción religiosa. Respecto al mismo, Otto insistirá en la advertencia de no caer en intentos de traducirlo en explicitaciones y conceptos. Más bien, se nos invitará a una indagación interior en la cual puedan ser detectados los elementos más específicos emergentes en derredor a la experiencia religiosa. Dicho de otro modo, y retomando la palabra vivencia para clarificarlo lo mayormente posible, se trataría de un abordaje de tipo psicológico en el cual se trataría de hacer patente lo que en el interior de nuestra persona surge ante una experiencia de tipo sagrada.

Este primer momento se lo denomina como sentimiento de criatura (Kreaturgefühl) (Otto, 2008, pág. 19). Momento del cual nos interesa hacernos eco a raíz del diálogo que este pensador llevará adelante con Friedrich Schleiermacher alrededor a lo que este hubo de concebir como sentimiento de absoluta dependencia (Gefühl der Abhängigkeit). En síntesis, este sentimiento se lo puede entender como hundimiento y desaparición ante la presencia tremenda de la divinidad, la cual solo puede ser concebida de forma indirecta desde el sentimiento como única fuente. En relación con esto se producirá la primera diferencia respecto a Schleiermacher, pues 
según Otto, aquel se mostró ambiguo a la hora de desarrollar su sentimiento de dependencia. Esto por dos motivos: el primero, por no precisar lo suficiente lo que quiso decir con dependencia, sentimiento que sería posible trasladar a muchos ámbitos de la vida cotidiana (Otto, 2008, pág. 22). Consecuencia de ello, Otto utiliza el término criatura a fin de distinguirlo de todos los sentimientos naturales de dependencia. En segundo término, su crítica irá dirigida al status con el cual Schleiermacher dotó a dicho sentimiento. En pocas palabras, este lo habría querido determinar desde un contenido propio, lo cual iluminaría sin más la categoría de lo religioso (Otto, 2008, pág. 23). Esto no se correspondería en nada desde lo comprendido por Otto respecto al sentimiento de criatura, al cual definirá como "momento subjetivo epifenomenal y un efecto" (2008, pág. 23). Por lo que cabe entender que allí nada propio puede determinarse, ningún contenido independiente respecto a aquello tremendo que hunde al creyente en un sentimiento indescriptible. Este objeto fuera del sujeto sintiente es precisamente el numinoso, el cual provoca en el ánimo de aquel su disminución como reflejo. Bajo este mismo espíritu, el psicólogo y filósofo William James nos dirá acerca del origen de los dioses griegos:

\footnotetext{
"es como si en la conciencia humana viviera la sensación de algo real, un sentimiento de algo efectivamente presente, una representación de algo que existe objetivamente, que es más profundo y de validez más universal que cualquiera de las sensaciones aisladas y particulares según las cuales se prueba la realidad..."(2007, pág. 276).
}

Consecuencia de lo anteriormente visto puede ir comprendiéndose de suyo que la idea de lo sagrado no será indagada y construida bajo las exigencias de un concepto. Su mismo carácter irracional lo impediría desde un primer momento. La cuestión más bien será esgrimida a partir de una determinación de tipo reactiva ante aquella presencia avasallante de lo numinoso. Una determinación que se explicita en el ánimo de aquel que experimenta dicha presencia, pero que no puede sobrepasar el límite en relación al mismo, de la claridad conceptual. No hay conocimiento de Dios, sino lo que se cree que es una experiencia de este, y aquí, el objetivo de Otto sería suscitarla 
desde lo que hemos denominado anteriormente una representación o simbolización ritual de carácter psicológica. Representación que por otro lado, posee una carga interpretativa sumamente intensa.

Este encuentro entre el sujeto-criatura y el objeto-numinoso se desarrollará en lo que Otto denominará como mysterium tremendum, segundo momento de lo numinoso (2008, pág.25). Efectivamente es allí donde se manifestará aquella determinación del sentimiento y el momento de "mayor accesibilidad" a la divinidad. No obstante, su carácter de misterio -como ha sido señalado-, lo torna inasequible desde conceptos y definiciones, esquivando de modo tajante al esfuerzo clarificador del entendimiento. Respecto al predicado sintético tremendum, se hace referencia a un temor de naturaleza específica, al cual los griegos denominaban $\sigma \varepsilon b \alpha \sigma t o ́ s$ (sebastós), significando con ello lo augusto, respetable y venerable, no perteneciente a ninguna categoría humana o animal. Temor en definitiva, exclusivamente religioso o también horror sagrado:

"De tal temeroso respeto y de su forma más burda, de este sentimiento de lo desasosegante que irrumpe en su primera palpitación en cualquier momento -que asoma como algo nuevo y extraño en el alma de la humanidad primitiva--, ha salido todo el desenvolvimiento histórico de la religión" (Otto, 2008, pág. 28)

Idea interesante en torno a lo divino en cuanto se atribuye a este pavor de naturaleza muy especial, una fuerza que tiende a la rememoración de "lo originario". Lo resuelto hasta aquí, presumimos, tendrá mayor fuerza dentro del orden de lo teórico una vez que asumamos la tarea de concebir dicha noción desde la perspectiva antropológica de Rene Girard, complementada con los aportes provenientes de la biología en Walter Burkert.

Ahora bien, para que la experiencia de lo numinoso se constituya de modo efectivo, resulta fundamental la participación de un tercer momento: el del mysterium fascinans (misterio fascinante). Allí, en contraste con lo tremendum del misterio sagrado -horror sagrado --, emerge el momento en cual se muestra atractivo y 
benéfico (fascinante). Otto lo considerará "el hecho más exclusivo y digno de consideración en la historia de la religión" (2008, p. 49), en tanto se lo habría de considerar como el pilar sobre el cual se edificaron todos los sistemas religiosos. Allí es donde reposa la idea de que lo sagrado pueda tener una influencia o intervención favorable para con el fiel, constituyéndose a su vez como el motivo por el cual se justifica lo ritual como práctica en las comunidades arcaica. El sentimiento religioso del anhelo, de tal forma, vive en lo fascinante; se manifiesta presente en la elevación del ánimo hacia lo sagrado.

Aquella justificación que la experiencia sagrada manifiesta en este momento de lo fascinante y su contraposición respecto a lo tremendo, nos sugiere algo de sumo valor en lo que concierne a la estructura misma de esta vivencia. Tremendo y fascinante a la vez, lo sagrado se manifiesta en el devoto bajo apariencias de notoria ambivalencia entre la repulsa y la atracción. Bajo de esta dinámica ambivalente, se precisará el concurso de ambos momentos para prosperar en un binomio de expectación entre lo tremendum y en lo fascinans que solamente encontraría explicación desde la experiencia misma en tanto su apariencia es de notable contradicción. ${ }^{11}$ Es de tal modo que ingresa aquí como tema de discusión, la cuestión de los medios por los cuales esto numinoso ha de encontrar expresión. Hasta aquí se ha hecho evidente que la construcción de una referencia con respecto a lo sagrado, responde más a un imperativo de sentido que de significado. Esto en razón de que nos hemos encontrado de frente con una noción que se resiste de forma radical a todo intento de definición taxativa. Otto así lo comprende, y bajo líneas generales, su obra responde a algo que puede denominarse como simbolización de lo sagrado, y no una constitución de tipo conceptual. Dicha simbolización ${ }^{12}$ vendría de la mano con aquel carácter irracional que propiamente compete al orden de lo divino y que solo puede ser suscitado en el ánimo del devoto desde la identificación de aquellas determinaciones que ofrecen el sentimiento específico de dicha experiencia.

\footnotetext{
11 "Dos emociones contradictorias entre sí, son la principal causa del colapso de la lógica aplicada a la descripción de la experiencia religiosa, puesto que la premisa que refiera a lo sagrado es de entrada ambigua, es decir, sin un significado claro y distinto, ya que rebasa la experiencia concreta que los sentidos tienen de las cosas, al no ser capaces de percibirlo en su totalidad". (Guacaneme, 2010. p. 295).

12 "Por símbolo no se debe entender una forma de lenguaje religioso, sino que todo lenguaje religioso es símbolo en tanto que remite a lo indefinible, es decir, a lo sagrado". (Guacaneme, p. 293).
} 
Para finalizar este abordaje en derredor a la idea de lo sagrado en Rudolf Otto, digamos en carácter de conclusión que el modo más adecuado de consignarlo será a partir de una simbolización de aquello que se manifiesta como inexpresable en el orden de los significados. Esto en razón de todo lo relacionado con lo divino se sitúa en un excedente de sentido que solamente puede ser indagado de forma indirecta, desde un rodeo en el cual lo que se determina es un efecto y no una causa. Lo que se pretende allí, como puede ser comprendido, no será la aprehensión de un significado que refiera a lo real, sino una interpretación que busque asimilar la experiencia lo más fielmente posible al ámbito sagrado. Es bajo dicho lineamiento que Eliade mencionará una "lógica del símbolo" (Eliade, 1974, p. 226), lógica que responde a un sentido, y no a significados. Pasaremos a continuación a considerar el modo en que este historiador y erudito de las religiones, habrá de desplegar este sentido de la experiencia sagrada.

\section{b) El abordaje fenomenológico de lo Sagrado en Mircea Eliade}

Mircea Eliade (1907 - 1986) fue un filósofo e historiador de las religiones nacido en Bucarest. Su obra, dado el formato enciclopédico y erudito que la caracteriza, ha repercutido grandemente en las disciplinas abocadas a lo religioso en general. En lo inmediato, nos dedicaremos a examinar sus trabajos más relevantes en lo que a la tematización de lo sagrado refiere. En lo concerniente al objetivo general de su obra, Eliade enunciará lo siguiente:

"La historia de las religiones se refiere a lo más esencialmente humano: la relación del hombre con lo sagrado. (...) Las crisis del hombre moderno son en gran parte religiosas en la medida en que suponen la toma de conciencia de una carencia de sentido" (Eliade, 1980, p. 67).

Bajo dicha premisa expondremos, aunque de forma esquemática, lo que este pensador comprendió por aquella relación entre el ser humano con lo sagrado a partir de los desarrollos teóricos considerados en su obra Lo sagrado y lo profano (1957). 
Dicho texto oficia perfectamente como puerta de entrada al pensamiento integral de Eliade en cuanto tornan explícitos sus métodos y objetivos generales.

Con el fin de evidenciar lo sustantivo de la relación profano-sagrado, Eliade tomará como referencia la existencia del ser humano "primitivo y tradicional", la cual se manifestaría sustancialmente atravesada bajo la fuerza irradiada por lo sagrado. En el prólogo ya es posible verificar la intención del autor, el cual enuncia que entre sus diversas metas emerge con protagonismo la de ofrecer un estudio introductorio y general al estudio fenomenológico e histórico de los hechos religiosos (Eliade, 2012, pág. 5). Con ello, concretamente lo que se intentará comprender es el comportamiento del homo religiosus, modalidad existencial que se ha de caracterizar por una simbología específica y expresiones valorativas que pondrían de manifiesto la estructura última de la conciencia humana. Es allí desde donde cobra un valor específico el plano de lo profano, el cual según Eliade, se presenta como nueva y por ende, posterior manifestación de la estructura constitutiva del hombre frente a lo sagrado como valor originario. Esto nos da un primer indicio sobre lo que este pensador habrá de comprender por lo sagrado, quien al considerarlo como estructura de la conciencia bajo la cual la humanidad hubo de relacionarse holísticamente con todo lo real, manifestará toda una serie de modos y concepciones propias.

Tiempo y espacio son dos maneras, por tomar un ejemplo, en que puede ser considerado lo específico de lo sagrado en el comportamiento de aquel homo religiosus. Cabe allí, ser referida una de sus obras más conocidas, El mito del eterno retorno (1949), en el cual y a rasgos generales, presenta la antigua concepción cíclica del tiempo desde la reactualización o imitación de antiguos hechos míticos, contraponiéndolos a la actual concepción del tiempo lineal, histórica y creativa del hombre moderno. En páginas posteriores trabajaremos esta categoría con mayor especificidad. Por el momento, y en función de lo visto hasta aquí, puede observarse, cómo lo sagrado va siendo asimilado a una cosmovisión en la cual gran parte de las categorías desde la que se construye asumen un carácter casi de hostilidad frente a la cotidianeidad y mundanidad de lo profano. Uno y otro, se revelan en mutua exclusión dadas las diferentes formas que tienen de abordar la realidad. Es a partir de esta 
relación de recíproca hostilidad, de separación ontológica entre lo sagrado y lo profano donde Otto, Eliade y gran parte del pensamiento contemporáneo construyen sus cimientos para los desarrollos y especulaciones sobre lo sacro. En función de ello, puede ser observado cómo lo sagrado considerado como lo absolutamente otro, es caracterizado bajo las más diversas cualidades, todas esencialmente atravesadas por el hilo común de lo que no es lo profano. Un partir desde lo más conocido -pues lo profano respondería a la cosmovisión del ser humano contemporáneo- ${ }^{13}$ hacia aquello lleno de misterio y planteado como lo inaprensible pero que por alguna razón, busca ser elucidado. Veamos en lo siguiente como Eliade trabaja esta oposición.

Respecto a la obra previamente indagada de Rudolf Otto (Lo Sagrado), el pensador rumano mostrará alguna reticencia al entender que allí opera un análisis del fenómeno de lo sagrado donde prevalecería su aspecto más irracional, negándole propiamente todo carácter racional al serle atribuido este a concepciones religiosas relativamente "actuales" como es el caso del cristianismo, el budismo, entre otras (2012, pág. 5). Como contraste, Eliade nos propone un abordaje integral de lo sagrado, en el cual sería posible adscribirle rasgos propiamente racionales desde el campo de la experiencia religiosa. La primera definición que se nos ofrecerá sobre dicha noción será en base a su oposición con lo profano. Oposición que se muestra consciente y voluntaria en el devoto a la hora de practicar la vivencia de la divinidad o experiencia de la hierofanía (manifestación e irrupción de lo sagrado en la naturaleza). Bajo tales condiciones, lo sagrado se corresponde con lo sustancialmente cargado de realidad y de ser, frente a lo profano, cargado de irrealidad. En base a esto, se hablará de lo sagrado como aquello ontológicamente saturado, situándose la experiencia humana del mismo como participación plena en el ser (Eliade, 2012, pág. 10). Lo profano y lo sagrado se presentan por ende, como dos modalidades existenciales -opuestas-- y de acuerdo a una de ellas, las sociedades primitivas articularían toda una ontología -lo sagrado como aquello saturado de ser- desde la cual concibieron lo total de lo real en su compleja constitución. Al respecto nos dirá Eliade: "El deseo del hombre primitivo de vivir en lo sagrado equivale, de hecho, a su afán de situarse en la realidad objetiva,

\footnotetext{
${ }^{13}$ Wunenburger atribuye esta situación a la desacralización del "hombre posmoderno" (2009).
} 
de no dejarse paralizar por la realidad sin fin de experiencias puramente subjetivas, de vivir en un mundo real y eficiente y no en una ilusión" (1961, p. 88). Aclaración que resulta fundamental a la hora de comprender cierto salto cualitativo en el abordaje sobre la noción que aquí nos interesa. De este modo, lo sagrado empezaría a ser indagado desde un plano de objetividad y no ya perteneciendo a lo puramente subjetivo o psicológico como lo había trabajado Otto. Hubo de resultar imprescindible para ello, el ascendente etnológico e histórico bajo el cual Eliade considero sus estudios.

De lo visto, puede ser deducida por parte del pensador rumano una clara tentativa de objetivación de lo sacro. Esto se advierte en su trabajo a partir de las categorías existenciales bajo los cuales comprende lo sagrado. Más allá de esto, lo que resulta importante destacar es la presencia absolutamente concreta de un enorme y complejo conjunto de prácticas, valores y costumbres desde las cuales la realidad misma es abordada y concebida, manifestándose como condición de posibilidad y acceso a la misma. Por otro lado, este conjunto no se trata en absoluto de algo supeditado meramente a la experiencia religiosa, sino de algo mucho más amplio en contraste al modo secular e institucional bajo el cual hoy se la concibe. Es de esta forma que en la cosmovisión sagrada es posible detectar mediante simbologías, procesos que refieren al origen del mundo, de la humanidad y sus prácticas -hasta las más mundanas-.

Una de las experiencias centrales en la modalidad existencial de lo sagrado es la referida al espacio. "Para el hombre religioso el espacio no es homogéneo; presenta roturas, escisiones: hay porciones de espacio cualitativamente diferentes de las otras" (Eliade, 2012, p. 15). De tal forma, el espacio considerado sagrado se constituye radicalmente como aquel que dota absolutamente de sentido a la permanencia en él en tanto habrá de ser concebido como centro o referencia que posibilita una distinción doble: una horizontal, en tanto existe un interior sagrado frente al exterior profano; y una vertical, a partir de cual se conciben los espacios propios de la divinidad (cielo, tierra e infierno). La manifestación de lo sagrado transforma el caos de un territorio en un cosmos habitable a partir de la consagración del mismo. En la experiencia profana 
del mundo, por el contrario, no existe orientación en su estructura ni rupturas que lo diferencien cualitativamente. Ejemplo actual y huella de esta valoración sagrada del espacio se da en la cosmovisión cristiana desde la iglesia, lugar donde se manifestaría lo absolutamente diferente en torno a la experiencia profana del espacio. Ahora bien, en la experiencia primitiva y sagrada, sea del espacio o en su generalidad, se da el agregado de un elemento que contribuye sustancialmente a su status de diferenciación. Esto es el elemento de lo fuerte, aquello que se despliega como poder, manifestación que puede ser traducida como kratofanía (1961, p. 69). Lo sagrado se concibe como fuente de poder, siendo comprendido este último de forma indiferenciada con aquello que es en su potencia ontológica.

Otra categoría existencial de suma relevancia en Eliade y para el trabajo que aquí se viene desarrollando es la referida a la noción de tiempo en el orden de lo sagrado y su inherente estructura cíclica. Dirá Eliade al respecto: "Todos los actos importantes han sido revelados ab origine por los dioses o héroes. Los hombres no hacen sino repetir infinitamente estos gestos ejemplares y paradigmáticos" (Eliade, 2011, pág. 47). En este sentido, lo que confiere realidad a un acto es la repetición de un arquetipo. La realidad misma se obtiene por repetición de lo sagrado. La importancia de este hecho, como será desarrollado con mayor detenimiento en el apartado siguiente, radica en el modo en que el ritual despliega su estructura y relación de sentido con lo sagrado, manifestando un hecho de carácter originario y fundante de las relaciones propiamente humanas. Como además podrá ser comprobado, en el contenido de aquella repetición se presenta un hecho tan frecuente como diversos son los sitios de los cuales procede. Este hecho, concretamente, se caracteriza por la violencia suscitada y representada en el rito del sacrificio, el cual reúne los dos elementos de tiempo y espacios sagrados que vienen siendo desarrollados desde la obra de Eliade.

Así entonces, el tiempo de un acto ritual por excelencia como lo es el sacrificial, por tomar un ejemplo arquetípico, ${ }^{14}$ procedería desde la repetición en referencia a un

\footnotetext{
${ }^{14}$ Una de las disciplinas que mayormente se ha ocupado de esta institución, por demás significativa en lo sagrado, es la sociología. La naturaleza social que dicho rito detenta en comunidades que lo practican, ha servido a pensadores como Emile Durkheim, Henri Hubert, George Bataille, entre otros, ubicarlo
} 
hecho originario, fundante del periodo o ciclo que le toca consagrar. En presencia de estas especulaciones, una respuesta al interrogante sobre el motivo de tal repetición y el valor de la misma debería ser indagada en lo propio del acto ritual, teniendo en cuenta su valor de ejemplaridad. De este modo, si se considera que el sacrificio procede de forma exclusiva por vías violentas, lo cual presupone como condición todo un saber de fondo -regulación estricta de lo ritual-, es coherente pensar que aquello imitado (el hecho arquetípico) responde a un hecho, situación o fenómeno de particular valor para los orígenes del grupo o comunidad y que en efecto, haya tenido por componente de importancia acontecimientos marcados por una violencia radical. Bajo dicha lectura, lo sagrado será asociado, a veces de manera indistinta, al fenómeno de la violencia, agregándose al aspecto irracional (Otto) y absolutamente real (Eliade) que vienen siendo considerados.

Con el fin de lograr una comprensión más acabada de lo Sagrado, trabajaremos a continuación con dos pensadores que lo han indagado en clave antropológica, permitiendo un acercamiento del mismo en el orden de las prácticas. Ello contribuirá a una consideración del fenómeno de lo sacro más allá de sus manifestaciones psíquicas y existenciales según lo hemos presentado desde Otto y Eliade.

\section{c) Los estudios antropológicos de lo sagrado en Rene Girard y Walter Burkert}

René Girard (1923 - 2015) fue un historiador, crítico literario y filósofo nacido en Aviñón. Su obra recorre las más diversas temáticas. Desde los estudios bíblicos, pasando por el análisis literario hasta la antropología cultural y religiosa. En esta última perspectiva nos enfocaremos para dar cuenta de su pensamiento acerca de la violencia y lo sagrado. Precisamente, estas últimas palabras, La violencia y lo sagrado (1972) son las que titulan al libro que aquí abordaremos.

como fundamental dentro de sus hipótesis de trabajo. La idea de que lo sagrado es el reverso de las primeras representaciones que la colectividad tiene de sí, vienen a ser mediadas por el acto material del sacrificio. Un texto canónico de esta vertiente es el publicado por Henri Hubert y Marcel Mauss originalmente en 1899 Se trata de: Ensayo sobre la naturaleza y la función del sacrificio. Trad. de Víctor Goldstein. Waldhuter, Bs. As., 2019.

En nuestro país, la vertiente sociológica de lo sagrado ha encontrado diversos desarrollos. Véase: Lorio, N. La potencia de lo sagrado y la comunidad. Un rastreo de Durkheim a Bataille en el Colegio de Sociología (2013). Revista de Filosofía: Areté. Vol. XXV, N 1, ISSN: 1016-913X. 
Una de las primeras aseveraciones de este pensador en la obra citada, es acerca del carácter indisociable que opera entre el fenómeno de la violencia y de lo sagrado. En tal aspecto, Girard le atribuirá a lo sagrado un rol de naturaleza claramente social al decir que "el terreno preventivo era el terreno religioso. La prevención religiosa puede tener un carácter violento. La violencia y lo sagrado son inseparables" (2011, pág. 69). Se puede hablar aquí de la dimensión catártica del sacrificio. Función social que por otra parte irá aparejada de una dimensión simbólica de carácter revelador al manifestarse como rememoración de un hecho originario y de un valor inconmensurable para la comunidad. El modus operandi de este ser indisociable de la violencia y lo sagrado estará dado por el desarrollo de un hacer en específico, el cual ya hemos considerado en páginas anteriores desde la práctica ritual del sacrificio. En el orden de la praxis, este rito comporta el acto consagratorio por excelencia. Es el que santifica un espacio, tornándolo cualitativamente distinto, y el que es repetido una y otra vez en la rememoración del hecho decisivo y fundante. El análisis que Girard Ileva adelante sobre la violencia en este aspecto, se comprende esencial al decir que ésta dentro del sacrificio se presenta "como elemento de análisis, por ser independiente, por lo menos en parte, de unas variables culturales con frecuencia desconocidas, mal conocidas, o menos bien conocidas, tal vez, de lo que suponemos" (Girard, 2011, pág. 12). De este modo, dicha relación de violencia y divinidad estaría presente en culturas tan numerosas como diversas, presentándose como un fenómeno revelador en lo que respecta a los modos en que la humanidad hubo de crear, desarrollar y fortalecer sus primeras instituciones.

Aquí quisiéramos rescatar algunas cuestiones. La primera de ellas, referida a que la violencia y lo sagrado se muestran como fenómenos indisociables. También, recordar que esta violencia habrá de expresarse de forma privilegiada en la institución del sacrificio bajo un aspecto de santidad. Segunda cuestión, tomar nota del valor que detenta esta violencia sagrada en el seno de la comunidad donde opera. En este caso, podríamos aludir un valor de tipo metafísico en el sentido de su simbolismo originario, manifestándose como fuente de todas las cosas, lo cual nos indica la importancia de su repetición ritual. Tercer y último detalle a notar, una presencia de tipo intercultural de 
dicha violencia, pues como el antropólogo lo atestigua, el ritual sacrificial opera en comunidades tan diversas como lejanas entre sí, desde los aztecas hasta los griegos.

Respecto a su devenir en Occidente, es importante señalar que hubo de operar cierto olvido de aquella función crucial del sacrificio. El filósofo francés nos dice en este sentido que "el punto de ruptura se sitúa en el momento en que la intervención de un sistema judicial independiente pasa a ser apremiante" (Girard, 2011, pág. 31), con lo cual la violencia es absorbida por un aparato secular que no traerá aparejado en la ejecución del castigo, el riesgo de una escalada de violencia marcada por la venganza (violencia intestina o negativa). Para que esto ocurriera, la construcción del principio de culpabilidad fue determinante. Con ello, se asocia el acto a la voluntad del individuo, y en consecuencia le cabrá una responsabilidad inherente. Pero con ello, también se trasluce algo de mayor importancia. El del manejo de la cuestión de la violencia bajo coordenadas muy diferentes. De esta manera, si lo sagrado funcionaba en el terreno preventivo de la violencia a fin de resguardar el orden social desde una canalización bajo el cual el sacrificio poseía un rol crucial (simbólica originaria y catártica), con la irrupción de un sistema judicial independiente, fue la aparición de la dimensión correctiva lo que de alguna forma debilitó sustancialmente al primero, y con ello un aspecto sustancial de la experiencia sagrada. A la luz de lo expuesto hasta aquí y con la cautela que amerita ser adoptada, estas palabras de Rudolf Otto con respecto al mysterium tremendum que se desarrolla en la experiencia numinosa, resultarán clarificadoras: "La racionalización de esta ira, que falsamente se suele llamar natural y es en verdad más bien totalmente no natural, es decir numinosa, tiene lugar cuando se la llena con los momentos ético-racionales de la justicia divina en la sanción y castigo de las faltas morales" (Otto, 2008, pág. 32).

Algo que también debería ser tenido en cuenta a luz de lo que Girard comprende por lo sagrado, es su relación con el saber teológico. En tal aspecto, cabría preguntarse si la teología no respondería a aquella tendencia racionalizante y en consecuencia, a una reducción de lo sagrado. Reducción que bien podría comprenderse como sublimación y agregado de aquellos predicados que Otto consideraba como esenciales sintéticos. En el pensamiento de Girard toda duda se 
disipa al respecto cuando se comprende que lo sagrado allí responde a una función de la cual el orden social no puede prescindir a riesgo de desintegrarse bajo una oleada de violencia intestina. En este sentido, no podría pertenecer al orden de lo especulativo, ni aun meramente a aquella dimensión simbólica que la sitúa como práctica originaria y esencial. Esto, en razón de que tal simbolismo de lo sagrado se despliega fundamentalmente en la dimensión específica de la praxis. Ritos, danzas, utilización de máscaras, cierre del ritual mediante el sacrificio, etc., forman parte de un repertorio que pertenece a lo sagrado en la puesta en acción de la memoria colectiva. Quizás sea el mito el que pueda ser catalogado como actividad mayormente ligada al orden especulativo en derredor de lo sagrado. ${ }^{15}$ Su relato generalmente ligado a hechos fundacionales del orden (cosmogónico, caso del famoso mito de la castración de Urano; o estrictamente del orden de lo social como el mito de Prometeo), nos refieren a una actividad plasmada en la oralidad y que tenían por función aquella rememoración de los orígenes.

Para finalizar esta exposición del pensamiento girardiano, no quisiéramos dejar pasar una serie de críticas que sobre este autor han sido elaboradas a partir de lo que se ha comprendido como exceso especulativo. En este sentido, se manifestarían en las principales conclusiones del filósofo francés grandes elucubraciones teóricas sin demasiadas posibilidades de ser logradas contrastaciones de carácter empírico. Esto, muy a su pesar, pues si nos detenemos en su obra, verificaremos la preocupación del autor por elaborar una "perspectiva empirista de los hechos religiosos" (Girard, 2011, pág. 44). Habiendo tomado nota de esto, hemos consideramos conveniente adoptar la perspectiva del siguiente pensador, en cuanto basará integralmente sus investigaciones en el campo disciplinar científico de la biología y la etología. No pretendemos con esto dar una justificación última de lo que aquí viene siendo indagado, sino adjuntarla como perspectiva para dar respuesta a aquellas críticas vituperantes de la obra del filósofo y antropólogo francés. A ellos nos abocaremos para dar cierre el presente capítulo.

15 “...lo único probado es que el mito y el rito, como formas de la tradición cultural, se combinan exitosamente" (Burkert, 2013, pág. 65) 


\section{César Ignacio Gonzalo}

Walter Burkert (1931 - 2015) fue un filólogo clásico y estudioso de la religión griega nacido en el estado de Baviera. La originalidad de este autor en derredor a su indagación sobre lo sagrado, responde a las investigaciones que de forma complementaria realizó desde la disciplina biológica y etológica. En pocas palabras, nos ofrece una perspectiva de la religiosidad desde la biología, lo natural y lo somático. En sus obras Homo necans (1972) y La creación de lo sagrado (1996), este autor nos ofrece una serie de estudios en los cuales el sacrificio cobra especial importancia a la hora de indagar en las raíces mismas de la práctica religiosa. ${ }^{16}$ Esto, en razón de que de forma similar a como René Girard lo comprende, el rito sacrificial emergería como variable presente en religiones distanciadas en orígenes y contexto. Con lo cual, aparece nuevamente como variable independiente de análisis para lograr una elucidación de la idea de lo sacro. La principal diferencia entre ambos autores radica en el modo de justificar esta omnipresencia. Si Girard lo ha de concebir desde la crítica literaria -interpretación de textos religiosos y del género trágico en el caso específico de la antigua cultura griega-- y el análisis de estudios etnográficos, Burkert lo desde la evolución biológica del ser humano centrándose en su conducta colectiva de carácter religioso, en la cual el sacrificio detenta una importancia reiteradamente señalada.

En torno a la estructura misma del sacrificio se verifica una rigurosa reglamentación, ${ }^{17}$ en la cual prevalece una secuencia tripartita que se plasma en un comienzo intrincado y adrede demorado, un desarrollo o núcleo horrendo (la experiencia numinosa) y un final sereno, dominado por la más estricta de las consideraciones y un halo positivo de restauración. Ahora bien, tras las huellas de esta práctica, Burkert detecta algo diferente a la rememoración de un hecho trascendente por su inusitada violencia y que a la postre permitió la consolidación del orden en el seno de la comunidad. Es allí justamente donde la obra de Girard cobra los matices especulativos de indagación señalados. La propuesta del filólogo alemán irá por otro

16 "La experiencia fundamental de lo sagrado es la matanza sacrificial. El homo religiosus actúa y adquiere conciencia de sí como homo necans" (Burkert, 2013, pág. 21). El término necans refiere a matanza. La fórmula homo necans puede comprenderse como "hombre que mata".

En páginas posteriores dirá respecto al sacrificio "que es la forma más antigua de la acción religiosa" (Burkert, 2013, pág. 37).

${ }^{17}$ En este sentido, Girard menciona la peligrosidad del "material que se manipula. [...] Lo sagrado es todo aquello que domina al hombre con tanta mayor facilidad cuanto que el hombre se cree capaz de dominarlo" (2011, pág. 41) 
camino, y al respecto dirá: "el punto central [de la matanza sacrificial] es siempre la experiencia de la muerte, ocasionada por la violencia humana en virtud de una necesidad predeterminada" (Burkert, 2013, pág. 35). ${ }^{18}$ Esta experiencia que determina al ser humano ante semejante práctica, es de una cotidianeidad tal, que puede resultar curiosa. Se trata del acto mismo de la ingesta, de la experiencia de la comida. No obstante, no será la ingesta profana la que interese a este estudioso, sino más bien su opuesto, la ingesta llevada delante de forma ritual en unas de las prácticas más antiguas concretadas por la humanidad, y específicamente por el hombre. Nos referimos con ello a la caza. A esta hipótesis, Burkert la denominará como explicación genética de lo sagrado (2013, pág. 36). Las pruebas que justifican dicha formulación responden a los distintos modos en que tribus pertenecientes ya al periodo paleolítico llevaban adelante sus rituales de caza. Si bien dicho acto no pertenece en sentido estricto a una ceremonia, sino a algo mucho más práctico, contingente, con un sentido mundanal como lo es la obtención de carne como alimento, Burkert entiende allí que la vivencia en conjunto de la caza por parte del grupo, posee una carga lo suficientemente intensa para provocar su necesidad de rememoración ${ }^{19}$ en actos representativos que recuperen aquella carga de intensidad y que a la vez, provoque lo absolutamente opuesto en tanto se está en estrecho contacto con la experiencia de mayor repulsión: la muerte. Cobraría asimilar bajo estas indicaciones, el sentir ambivalente de lo sagrado del mysterium tremendum/mysterium fascinans. En derredor del sentimiento de culpa ante el animal asesinado se nos dirá: "En la base de todo está el miedo que, en vista de la realidad de la muerte, inspira el futuro: el acto cruento eran necesario para la vida, pero no es menos necesario que nazcan nuevas vidas" (Burkert, 2017, pág. 41).

Otro de los rasgos que sitúan a este pensador en una posición diferente a la de Girard acerca del modo en que lo sagrado hubo de desplegarse desde el desarrollo civilizatorio es que este último lo entenderá como un camino de talante sublime en el cual opera la paulatina desaparición de la víctima sacrificial como categoría y de la

\footnotetext{
${ }^{18}$ La cursiva es mía.

${ }^{19}$ Platón en el Critias (119d), mencionará respecto a su Atlántida ficticia esta relación entre la caza y el sacrificio.
} 
práctica misma de tal rito. Por el contrario, Burkert entenderá que en vistas del refinamiento que la humanidad hubo de conseguir a partir de ciertos avances, debió recurrir a la suscitación de conflictos que aseguren periódicamente el abastecimiento de víctimas. Como ejemplo de este progreso de la violencia sagrada "se exagera la oposición entre los sexos, [...] el conflicto generacional adquiere tintes no menos dramáticos en los rituales de iniciación. Privada del objeto de caza externo, la sociedad secreta puede convertir en víctima al propio iniciando" (Burkert, 2017, pág. 86). La máxima expresión en el orden secular de dicho "progreso", Burkert lo fijará en la pena capital entendida ella como suma manifestación del poder del Estado.

Baste esta última indicación para dar cierre a las indagaciones llevadas a cabo sobre lo sagrado en la actualidad. Nos interesó allí, el modo en que lo sagrado como noción ha llegado a un importante grado de secularización, culminando un camino en el cual ha desarrollado para sí una liberación de sentido de suma importancia en la tarea de ser concebida de forma autónoma respecto a otros modos de expresión religiosa. Con ello, puede decirse que ha sido allanado el camino en el objetivo de dar con una idea concreta de lo sagrado y así verificar las formulaciones hipotéticas que dieron motivo al presente escrito.

\section{Conclusión}

Tras haber indagado sobre algunas de las más importantes corrientes que en la contemporaneidad se ocuparon sobre la noción de lo sacro -las cuales lejos se encuentran de agotarla- ${ }^{20}$ pueden ser esbozados algunos lineamientos en lo concerniente a su construcción como objeto de estudio.

Inicialmente, en lo que refiere a su relación con el fenómeno religioso, la presencia del cristianismo en la doctrina de Rudolf Otto es innegable, interviniendo constantemente en su discurrir acerca de una noción que reclamaba cada vez más, un campo propio de significaciones y sentido. En el centro de esta exigencia, hubo de ser iluminado un elemento crucial de la noción de lo sacro: su inherente irracionalidad.

\footnotetext{
20 Para una descripción exhaustiva de las corrientes y pensadores que se encargaron de trabajar lo sagrado en la contemporaneidad, ver la segunda parte de la obra citada de Wunenburger, J. J. Teorías de lo sagrado: pp. $81-85$.
} 
Esta cualidad comenzó por dotar de nuevos significados a una idea que hasta el momento se mostraba bajo cierta ambigüedad, referida al sentimiento religioso sin más. Esta ínsita irracionalidad señalada por Otto, abrió todo un camino de reflexiones e interrogantes respecto a lo que propiamente pertenecía al campo de lo sagrado y que será recorrido luego por Eliade desde dos perspectivas que pueden comprenderse como fenomenológicas, pero que se diferencian en la naturaleza de los hechos que estudian (que en el fondo, no dejan de ser el mismo). En el caso de Otto, nos enfrentamos a una fenomenología de los hechos internos de la conciencia en presencia de lo sagrado; mientras que en Eliade, los hechos descriptos y reflexionados, refieren a la conducta del homo religiosus. En otras palabras, a la exteriorización de aquellos hechos internos, fluctuantes y materializados en las categorías de espacio y tiempo sagrado, como fue desarrollado en el historiador rumano. Emergieron allí, diversas categorías psíquicas y existenciales bajo las cuales ha de comprenderse la conducta del homo religiosus, sujeto que al decir de Eliade, encuentra su punto de anclaje en la realidad sagrada. Doble rostro (repulsión/atracción), tiempo de repetición, espacio cualitativo, entre otras, tomaron forma como elementos propios de una noción que fue cobrando cada vez mayores contrastes en tanto podían ser integradas ambas perspectivas bajo una descripción y reflexión sobre la fenomenalidad interna (Otto) y externa (Eliade) de la experiencia sagrada.

Lo sacro considerado por Otto desde diferentes categorías psíquicas (mysterium tremendum, mysterium fascinans, lo enorme, majestas, entre otros) vimos que se encuentra fundado esencialmente por una experiencia que le pertenece en lo más profundo: lo numinoso. Insensata, terrible, terrorífica (horror sagrado), son algunos de los predicados que se le atribuye a tal experiencia bajo la referencia de aquel neologismo. Por otro lado, también opera como edificante y benefactora de la condición humana. Doble aspecto que en la lectura realizada por Otto se comprende justamente desde el binomio mysterium tremendum/mysterium fascinans y que responde a la estructura misma de lo numinoso.

Por su parte, en su afán de exponer los modos existenciales del homo religiosus, Mircea Eliade nos permitió comprender las formas en que la cosmovisión 
sagrada comprendía la totalidad de lo real. Modalidades que se anteponen de modo radical a la concepción profana del mundo, el cual es caracterizado por un vacío ontológico solo posible de ser sostenido por la periodicidad de los actos sagrados (entre los cuales mencionamos al sacrificio con especial énfasis), son las de tiempo y espacio. De este modo, frente a la irracionalidad propia de la experiencia sagrada según lo considera Otto en su fenomenalidad interna, Eliade nos propone una perspectiva constructiva de aquella, tomando lo que de racional detenta en su propia lógica. Para lograr elucidar este aspecto "positivo" de lo sacro, fue necesario hacer hincapié en la exterioridad de la experiencia sagrada, viéndose reflejada en las instituciones que gesta a partir de prácticas rituales y que torna en objeto discursivo a través del mito. De lo irracional a esta faceta constitutiva de lo sacro, lo que permanece como acuerdo entre ambos pensadores es el fundamento bajo el cual consideran tal noción. Lo sagrado en tal sentido, nunca deja de estar en las antípodas de lo profano. Es en esta separación tajante, que sin embargo y por el mismo motivo tornan inseparables, donde lo sagrado encuentra anclaje para ser teorizado.

Una vez consideradas las dimensiones internas y externas de la experiencia sagrada, pasamos a trabajarla desde un abordaje que hemos denominado antropológico en virtud de lo que a sus exponentes interesó mostrar de dicha noción. Fue allí donde pudo ser explicitado de forma esquemática su aspecto funcional y social, lo cual terminó por alejarnos de aquella aseveración en la cual se le atribuía una total irracionalidad. A su vez, ello nos permitió acercarnos a una perspectiva más constructiva de lo sagrado en el sentido de corroborarla como un modo específico de concebir la realidad humana y las modalidades en que esta ha llevar adelante sus relaciones más esenciales. En este sentido, es posible seguir una línea de trabajo con lo desarrollado por Eliade. Con ello, pudo comprobarse una presencia común y estructural entre diversas culturas respecto de aquel conjunto de prácticas. Desde allí, afirmar la omnipresencia de la violencia en la experiencia sagrada en virtud de una serie de funciones que específicamente le competen. Estas funciones, por demás fundamentales, son: erradicar la violencia intestina del seno de la comunidad a partir de otro acto de violencia, la cual se enmarca profundamente en el rito desde 
mecanismos y regulaciones muy precisas; el de manifestarse como participación en lo mayormente cargado de realidad en cuanto remite al hecho originario y fundante (dimensión metafísica u ontológica); por último, el de lograr la cohesión del grupo social a partir de la concreción de un único acto de violencia santa en el cual todos participan (dimensión catártica de lo social).

Considerado ello, y a partir de los distintos abordajes aquí expuestos pueden ser vislumbrados diferentes aspectos de lo sagrado, los cuales tendrán mayor énfasis en uno u otro pensador. En primer lugar, su cualificación como fundamento. Sea del orden social, de las instituciones, de lo simbólico o de la condición humana misma, su presencia remite a la condición misma de la experiencia pues constituye la referencia bajo la cual la humanidad se dota de categorías esencialísimas para la aprehensión de lo real. A partir de esto es que en numerosas ocasiones será considerado como lo originario. En este aspecto cobra relevancia el abordaje de Otto para comprender la estructura de la vivencia interna de esta experiencia. En segundo lugar, su realización es esencialmente colectiva, en el sentido de que precisa del concurso de todos los componentes que se deben a lo sagrado para poder ser suscitada. Es allí donde el proceder ritual cobra un rol fundamental, pues su más íntima disposición es la de lograr posiciones y ejecuciones fijas, previsibles y procesuales. Una experiencia individual de lo sagrado remite a modos experienciales religiosos diferentes (toda idea teísta de dios, por ejemplo), pero nunca a lo propiamente sagrado. Aquí son reveladores los estudios antropológicos de Girard y Burkert, mientras que los dos anteriores (Otto, Eliade) solo se ocupaban de una indagación personal de lo sacro, lo cual representa una gran ausencia conceptual en lo que a la comprensión de lo sagrado refiere. En tercer lugar, se hizo frecuente la presencia del fenómeno de la violencia para que el acto sagrado pueda ser suscitado. Sea violencia real (caso del sacrificio) o figurativa (simulaciones en el caso de comunidades agrarias, fiestas, danzas, etcétera), su presencia es conditio sine qua non para que realmente lo sagrado se concrete. Nuevamente fue desde los aportes de la antropología donde esta dimensión nos fue revelada, pues era necesario primero evidenciar su aspecto colectivo. En cuarto y último lugar, el modo en que lo sagrado ha de encontrar 
expresión es a través de lo simbólico. En razón de ello, no podrá ser captado a partir de ideas claras y distintas. El medio por excelencia bajo el cual habrá de ser referido es a través del mito. La desfiguración narrativa propia del mito, vendría dado por aquel aspecto de "irracionalidad" indicado por Otto, en tanto lo que se refiere son relatos bajo una lógica que dista de ser apofántica. De este modo, no es descabellado asumir las modalidades existenciales trabajadas por Eliade para dar con una lectura clarificadora del mito, teniendo en cuenta además lo que Girard hubo de mencionar sobre la importante carga de sublimación que media todo acto sagrado teniendo en cuenta su origen "vergonzante", el de una violencia inusitada.

Así entonces, concluimos este artículo afirmando que en el pensamiento contemporáneo lo sagrado encontró diversas formas de ser abordado y tematizado, siendo por momentos fruto de un esfuerzo sistemático y continuo en el tiempo (téngase en cuenta la existencia del colegio de sociología sagrado fundado en Francia en 1937). Sea desde disciplinas como la psicología, desde la Historia, o de la antropología, entre otras, esta noción ha captado el interés de pensadores de las más diversas procedencias. Dentro de este carácter multidisciplinario de lo sacro, toma especial relevancia un punto en el que gran parte de aquellas convergen, el de su estructura binaria en relación con lo profano. Vimos que en el caso de Otto, lo sagrado es aquello signado por la terrible carga de lo numinoso, experiencia esencialmente irracional, en contraste con lo profano que distingue de forma clara y distinta (en este sentido llama la atención que el mismo Otto considere al cristianismo como una religión constitutivamente racional); del lado de Eliade, lo sagrado es aquello absolutamente otro en tanto se encuentra cargado de la única realidad posible: la que materializa la comunicación entre humanos y la divinidad. Por el lado de Girard y Burkert, la cuestión empieza a tomar mayor claridad, pues en tanto lo sacro sea relacionado de forma indisoluble con el fenómeno de la violencia, empiezan a ser atisbados los motivos por los cuales se lo considera como algo que no puede ser comprendido "desde adentro". Lo profano toma las formas de la sociedad secularizada, sumida en la cotidianeidad del trabajo y otras ocupaciones. La violencia allí no tiene lugar, hasta el momento en que se desborda a pesar suyo. Es esta 
La tematización de lo sagrado en el pensamiento contemporáneo

situación la que la violencia sagrada busca obstaculizar desde un terreno preventivo. Surge allí la dificultad suscitada por una comprensión positiva de la violencia en el sentido de que pueda poseer cualidades de constitución dentro del orden social. Creemos que es esta la problemática esencial que constituye a lo sacro, sea como fenómeno en sí, sea como objeto de especulaciones de todo tipo. Problema que interpela en lo más profundo de quién intente desentrañar sus elementos y que de alguna manera hoy persiste en la ambigüedad misma que el término adolece. 


\section{Bibliografía}

BURKERT, Walter (2014) Homo necans. Interpretación de ritos sacrificiales y mitos de la antigua Grecia. (Jiménez Buzzi., Trad.). Barcelona: Acantilado

BURKERT, W. (2017) La creación de lo sagrado. La huella de la biología en las religiones antiguas. (Mastrangelo, S., Trad.) Barcelona: Acantilado.

ELIADE, M. (1974). Tratado de la historia de las religiones. Tomo II. (Madinaveitia A. Trad). Madrid: Cristiandad.

ELIADE, M. (1980). La prueba del laberinto. (Valiente, J., Trad.). Madrid: Cristiandad. ELIADE, M. (2011) El mito del eterno retorno. (Anaya, R., Trad.). Madrid: Alianza.

ELIADE, M. (2012) Lo profano y lo sagrado. (Gil, L., Trad.). Buenos Aires: Masónicas.

GIRARD, R. (2011) La Violencia y lo Sagrado. (Jordá, J., Trad.) Barcelona: Anagrama.

GUACANEME, J. P. (2010) Orígenes y simbología de lo sagrado en el pensamiento de Rudolf Otto. En: FRANCISCANUM (Vol. LII), № 153, 2010.

JAMES, W. (2007) Variedades de la experiencia religiosa. Un estudio de la Naturaleza Humana. (Yvars J. F., Trad.). Madrid: Trotta.

OTTO, R. (2008). Lo sagrado. (García Belsunce, Trad.) Buenos. Aires: Claridad.

SCHLEIERMACHER, F. (2002). Sobre la religión: Discursos a sus menospreciadores cultivados. (Arsenio Ginzo Fernández, Trad.). Madrid: Tecnos.

WUNENBURGER, J. J. (2006). Lo Sagrado (Bauzá B., Trad.). Buenos Aires: Biblos.. 